\title{
A informática no suporte ao desenvolvimento do processo ensino-aprendizagem na educação básica no Brasil
}

Carlos Eduardo Moreno

Sampaio

Liliane Aranha Oliveira

Vanessa Nespoli

Palavras-chave: inclusão digital; acesso à Internet; escolas; informática na educação; informatização; censo escolar.

\section{Resumo}

Sustenta que o acesso das escolas às novas tecnologias de informação poderá converter-se num poderoso instrumento para a superação de deficiências crônicas do sistema educacional brasileiro, sobretudo na educação básica. Nesse contexto, o processo educacional deve ser criativo e flexível, propiciando a criação de ambientes de aprendizagem que incorporem as novas tecnologias, colocando-as a serviço da formação de cidadãos críticos e produtivos. A criação desses novos ambientes de aprendizagem e sua ação eficiente exigem não só a implantação de uma infra-estrutura de laboratórios de informática, a utilização da rede mundial de computadores e de aplicativos facilitadores da aprendizagem, mas sobretudo alterações no papel dos principais atores do processo ensino-aprendizagem: a escola, o professor e o aluno.

Um país desenvolvido não existe sem um povo desenvolvido e educado. A promoção do desenvolvimento humano, em suas múltiplas dimensões, passa, obrigatoriamente, pela oferta de uma educação de qualidade, acessível a todos e comprometida com as exigências do mundo atual. $\mathrm{O}$ desenvolvimento socioeconômico sustentável de uma nação não pode prescindir de uma educação que acompanhe e impulsione as mudanças e, ao mesmo tempo, se aproprie das tecnologias disponíveis - uma educação capaz de contribuir para a inclusão social e para a construção de um saber que dê conta da gigantesca tarefa de imprimir as transformações necessárias para a inserção do País, de forma soberana e competitiva, no mercado mundial.

Neste contexto, o processo educacional deve ser criativo e flexível, propiciando a criação de ambientes de aprendizagem que incorporem as novas tecnologias, colocando-as a serviço da formação de cidadãos críticos e produtivos. O argumento central deste texto sustenta que o acesso das escolas às novas tecnologias de informação poderá converter-se num poderoso instrumento para a superação de deficiências crônicas do sistema educacional brasileiro, sobretudo na educação básica.

A criação desses novos ambientes de aprendizagem e a sua ação eficiente exigem não só a implantação de uma infra-estrutura de laboratórios de informática, a utilização da rede mundial de computadores e de aplicativos facilitadores da aprendizagem, mas sobretudo alterações no papel dos principais atores do processo ensino-aprendizagem: a escola, o professor e o aluno. De um lado, a escola promovendo as condições e o professor se apropriando rápida e profundamente das novas ferramentas colocadas à sua disposição para a tarefa educativa; do outro lado, o aluno motivado a assumir 
uma postura crítica, reflexiva e investigativa diante dos desafios e das novas oportunidades.

A inclusão digital virou expressão da moda, muitas vezes usada sem o exato entendimento do seu significado. Inclusão digital é, entre outras coisas, escolarização digital, ou seja, a aprendizagem necessária para que o indivíduo circule e interaja com o mundo das mídias digitais, como consumidor e como produtor de seus conteúdos e processos. Para isto, computadores conectados em rede e softwares específicos são instrumentos imprescindíveis no mundo da educação, do trabalho, nos novos cenários de circulação de informação e nos processos de comunicação.

Dizer que inclusão digital é somente oferecer computadores seria equivalente a afirmar que apenas carteiras, giz e quadro-negro garantiriam a escolarização e o aprendizado dos alunos. É necessária a atuação efetiva e qualificada dos professores, integrada a uma programação escolar que oriente o conhecimento e o trabalho nesses espaços. Portanto, a oferta de equipamentos é condição necessária, mas não suficiente para se realizar uma verdadeira inclusão digital de nossos jovens.

A base de dados do Censo Escolar permite a avaliação de alguns aspectos da inclusão digital que está ocorrendo nas escolas brasileiras. Com essas informações é possível estabelecer o perfil das condições de infra-estrutura instalada e, na percepção do responsável pela escola, se esses recursos estão sendo usados para fins pedagógicos.

Há, no Brasil, cerca de 210 mil escolas de educação básica, das quais 83\% pertencem à rede pública; essa distribuição caracteriza o sistema educacional brasileiro como majoritariamente público. No setor privado observa-se uma estabilidade no número de matrículas, que vem se mantendo em torno de 6,8 milhões na última década.

Tabela 1 - Número de Escolas de Educação Básica por Condição de Existência de Computador, segundo as Regiões Geográficas - Brasil 2004

\begin{tabular}{|c|c|c|c|c|c|c|c|c|c|}
\hline \multirow{3}{*}{$\begin{array}{l}\text { Unidade } \\
\text { geográfica }\end{array}$} & \multicolumn{9}{|c|}{ Escolas de Educação Básica } \\
\hline & \multirow{2}{*}{ Total } & \multirow{2}{*}{ Pública } & \multirow{2}{*}{ Privada } & \multicolumn{3}{|c|}{ Com computador } & \multicolumn{3}{|c|}{ Sem computador } \\
\hline & & & & Total & Pública & Privada & Total & Pública & Privada \\
\hline Brasil & 210.094 & 174.894 & 35.200 & 77.859 & 51.927 & 25.932 & 132.235 & 122.967 & 9.268 \\
\hline Norte & 26.197 & 24.888 & 1.309 & 4.084 & 3.328 & 846 & 22.113 & 21.650 & 463 \\
\hline Nordeste & 89.259 & 78.922 & 10.337 & 14.351 & 8.740 & 5.611 & 74.908 & 70.182 & 4.726 \\
\hline Sudeste & 57.553 & 41.026 & 16.527 & 36.532 & 22.748 & 13.784 & 21.021 & 18.278 & 2.743 \\
\hline Sul & 26.778 & 22.100 & 4.678 & 16.393 & 12.678 & 3.715 & 10.385 & 9.422 & 963 \\
\hline Centro-Oeste & 10.307 & 7.958 & 2.349 & 6.499 & 4.523 & 1.976 & 3.808 & 3.435 & 373 \\
\hline
\end{tabular}

Fonte: MEC/Inep

Entre as 210 mil escolas, apenas 37\% (77.859) possuem computador e dois terços delas pertencem à rede pública (51.927). Para o universo de escolas públicas, aquelas que possuem computador representam $30 \%$. Entre as escolas privadas este percentual corresponde a 74\%.

A análise dos dados por região mostra que o acentuado grau de desigualdade regional também está presente na informatização das escolas brasileiras de educação básica. Nas Regiões Sul, Centro-Oeste e Sudeste, mais de 60\% das escolas de educação básica possuem computador. O destaque fica para o Distrito Federal, onde 99\% das escolas públicas disponibilizam esse recurso. Por outro lado, nas Regiões Norte e Nordeste, este percentual não ultrapassa 16\%. No Piauí, somente 8\% das escolas possuem computador.

Os dados do Censo Escolar também permitem identificar as escolas que possuem computadores interligados em rede local. Entre as escolas públicas que possuem computador apenas 28\% (14.348) estão nessa condição, e entre as escolas privadas esse percentual é de 42\% (11.010). 
Tabela 2 - Número de Escolas de Educação Básica com Computador por Condição de Existência de Rede Local, segundo as Regióes Geográficas - Brasil 2004

\begin{tabular}{|c|c|c|c|c|c|c|c|c|c|}
\hline \multirow{3}{*}{$\begin{array}{l}\text { Unidade } \\
\text { geográfica }\end{array}$} & \multicolumn{9}{|c|}{ Escolas de Educação Básica com computador } \\
\hline & \multirow{2}{*}{ Total } & \multirow{2}{*}{ Pública } & \multirow{2}{*}{ Privada } & \multicolumn{3}{|c|}{ Com rede local } & \multicolumn{3}{|c|}{ Sem rede local } \\
\hline & & & & Total & Pública & Privada & Total & Pública & Privada \\
\hline Brasil & 77.859 & 51.927 & 25.932 & 25.358 & 14.348 & 11.010 & 52.501 & 37.579 & 14.922 \\
\hline Norte & 4.084 & 3.238 & 846 & 1.058 & 682 & 376 & 3.026 & 2.556 & 470 \\
\hline Nordeste & 14.351 & 8.740 & 5.611 & 4.309 & 2.265 & 2.044 & 10.042 & 6.475 & 3.567 \\
\hline Sudeste & 36.532 & 22.748 & 13.784 & 13.192 & 7.252 & 5.940 & 23.340 & 15.496 & 7.844 \\
\hline Sul & 16.393 & 12.678 & 3.715 & 4.783 & 3.127 & 1.656 & 11.610 & 9.551 & 2.059 \\
\hline Centro-Oeste & 6.499 & 4.523 & 1.976 & 2.016 & 1.022 & 994 & 4.483 & 3.501 & 982 \\
\hline
\end{tabular}

Fonte: MEC/Inep

Um terceiro elemento importante na avaliação da infra-estrutura de informática é o acesso à rede mundial de computadores. Os dados do Censo
Escolar de 2004 revelam que, no universo das escolas com computador, apenas 45\% das escolas públicas e $67 \%$ das escolas privadas contam com acesso à Internet.

Tabela 3 - Número de Escolas de Educação Básica com Computador por Condição de Conexão à Rede Mundial de Computadores, segundo as Regiões Geográficas Brasil 2004

\begin{tabular}{|c|c|c|c|c|c|c|c|c|c|}
\hline \multirow{3}{*}{$\begin{array}{l}\text { Unidade } \\
\text { geográfica }\end{array}$} & \multicolumn{9}{|c|}{ Escolas de Educação Básica com computador } \\
\hline & \multirow{2}{*}{ Total } & \multirow{2}{*}{ Pública } & \multirow{2}{*}{ Privada } & \multicolumn{3}{|c|}{ Com Internet } & \multicolumn{3}{|c|}{ Sem Internet } \\
\hline & & & & Total & Pública & Privada & Total & Pública & Privada \\
\hline Brasil & 77.859 & 51.927 & 25.932 & 41.143 & 23.526 & 17.617 & 36.716 & 28.401 & 8.315 \\
\hline Norte & 4.084 & 3.238 & 846 & 1.298 & 750 & 548 & 2.786 & 2.488 & 298 \\
\hline Nordeste & 14.351 & 8.740 & 5.611 & 6.086 & 3.137 & 2.949 & 8.265 & 5.603 & 2.662 \\
\hline Sudeste & 36.532 & 22.748 & 13.784 & 24.289 & 14.171 & 10.118 & 12.243 & 8.577 & 3.666 \\
\hline Sul & 16.393 & 12.678 & 3.715 & 6.721 & 4.065 & 2.656 & 9.672 & 8.613 & 1.059 \\
\hline Centro-Oeste & 6.499 & 4.523 & 1.976 & 2.749 & 1.403 & 1.346 & 3.750 & 3.120 & 630 \\
\hline
\end{tabular}

A integração desses três elementos presença do computador, conexão em rede local e acesso à Internet - estabelece o conjunto ideal de recursos de infra-estrutura informacional para que se processe uma mudança efetiva no processo de ensinoaprendizagem, criando condições para uma genuína "alfabetização digital" da atual geração de estudantes.

Estas condições somente são preenchidas hoje por 21.398 escolas de educação básica, das quais 52\% são públicas (11.310) e 48\% são privadas (10.088), mas, além da disponibilidade da infra-estrutura "ideal", é necessário que as escolas façam uso pedagógico dessas tecnologias. No universo das escolas com essas facilidades conjugadas, 19.253 (90\%) declararam fazer uso pedagógico da informática. Apenas 9.772 são públicas.

Considerando que o processo de informatização das escolas brasileiras de educação básica ainda está iniciando, com significativo atraso em relação a outros países em estágios similares de desenvolvimento, a utilização para fins pedagógicos, 
mesmo ocorrendo com microcomputadores isolados, já se apresenta como uma ação bastante positiva. Nessas condições, sobe para 27 mil o número de escolas públicas entre as 51 mil que possuem computador, que estão fazendo uso pedagógico desse recurso independentemente de eles estarem interligados em rede local ou com acesso à Internet.

Tabela 4 - Número de Escolas de Educação Básica com Computador por Condição de Utilização Pedagógica da Informática, segundo as Regiões Geográficas - Brasil 2004

\begin{tabular}{|c|c|c|c|c|c|c|c|c|c|}
\hline \multirow{3}{*}{$\begin{array}{l}\text { Unidade } \\
\text { geográfica }\end{array}$} & \multicolumn{9}{|c|}{ Escolas de Educação Básica com computador } \\
\hline & \multirow{2}{*}{ Total } & \multirow{2}{*}{ Pública } & \multirow{2}{*}{ Privada } & \multicolumn{3}{|c|}{ Com uso pedagógico } & \multicolumn{3}{|c|}{ Sem uso pedagógico } \\
\hline & & & & Total & Pública & Privada & Total & Pública & Privada \\
\hline Brasil & 77.859 & 51.927 & 25.932 & 46.448 & 27.205 & 19.243 & 31.381 & 24.697 & 6.684 \\
\hline Norte & 4.084 & 3.238 & 846 & 2.128 & 1.534 & 594 & 1.951 & 1.700 & 251 \\
\hline Nordeste & 14.351 & 8.740 & 5.611 & 8.441 & 4.400 & 4.041 & 5.897 & 4.330 & 1.567 \\
\hline Sudeste & 36.532 & 22.748 & 13.784 & 22.662 & 12.224 & 10.438 & 13.867 & 10.521 & 3.346 \\
\hline Sul & 16.393 & 12.678 & 3.715 & 9.718 & 7.000 & 2.718 & 6.670 & 5.674 & 996 \\
\hline Centro-Oeste & 6.499 & 4.523 & 1.976 & 3.499 & 2.047 & 1.452 & 2.996 & 2.472 & 524 \\
\hline
\end{tabular}

Fonte: MEC/Inep

Nota: 30 escolas não declararamo tipo de utilização que fazem do computador.

Mas é importante reforçar a idéia de que colocar computadores nas escolas não significa informatizar a educação e sim apenas disponibilizar aos professores e alunos as tecnologias de informática. Informática na educação representa a construção do conhecimento a partir da interação alunoinformática-professor, num ambiente participativo e envolvente, de forma a permitir que essas facilidades se transformem efetivamente em ferramentas úteis para o processo de ensino-aprendizagem, dentro e fora da sala de aula.

Além da infra-estrutura de informática, é importante que o professor se sinta confortável para desempenhar seu papel nesse novo ambiente, onde ele passa da posição de detentor do saber para a de mediador e orientador na construção do saber. Essa condição somente será possível de ser alcançada se o professor vivenciar a mesma experiência na construção do seu próprio saber. Ele deverá ter o entendimento de que a informática, como ferramenta que é, representa uma aliada e jamais uma concorrente da sua importante função.

O repensar da metodologia e da prática de ensino se torna inevitável. O papel da escola como locus orientador na utilização das tecnologias de informática como ferramenta na construção do conhecimento é imprescindível numa sociedade onde as carências econômico-sociais impedem a maioria da população do acesso às novas tecnologias de informação, principalmente aquela parcela que é atendida pelas escolas públicas. Ou seja, a escola pública tem um papel estratégico e insubstituível na promoção da inclusão digital, que vem se tornando cada vez mais uma condição sine qua non para a inclusão social.

A realização dessas mudanças - envolvendo (i) o aparelhamento das escolas com uma infra-estrutura adequada de informática; (ii) a formação de professores habilitados no manuseio dessa nova ferramenta; (iii) a capacitação continuada dos professores em metodologias e práticas de ensino que utilizam as tecnologias de informática - é condição básica para o sucesso do processo de ensino-aprendizagem na sociedade da informação em que vivemos. A eficiente utilização dos recursos de informática propicia ao aluno um novo olhar sobre o ambiente escolar, integrado ao mundo que o cerca, num dinamismo prazeroso que faz da vivência em sala de aula algo mais próximo da realidade.

Nesse sentido, ainda existem alguns paradigmas que precisam ser quebrados. A velocidade da evolução tecnológica atropelou o tempo das adaptações culturais e mudanças de atitude, principalmente aquelas que estabeleciam que a escola era a detentora da informação e os professores os detentores do 
saber. Numa perspectiva freireana, tornou evidente o anacronismo da concepção "bancária" da educação, segundo a qual o educando é um receptor passivo do conhecimento depositado pelo professor.

Esse imaginário ainda resiste e contribui, em muito, para a rejeição da adoção das novas tecnologias de informação nas práticas pedagógicas, impedindo que os efeitos positivos da informática sejam alcançados de maneira plena no ambiente educacional. As crianças e os jovens vivenciam um mundo onde a informática cada vez mais faz parte dos processos produtivos e das relações sociais. Para atender a sua missão de formar cidadãos aptos a atuar de forma autônoma e criativa na sociedade da informação, a educação escolar precisa passar por mudanças estruturais e curriculares. A tecnologia não causa mudanças apenas no que fazemos, mas também em nosso comportamento, na forma como elaboramos conhecimentos e no nosso relacionamento com o mundo.

Informatizar as escolas é fazer com que o aluno aprenda com a tecnologia, aprenda usando as tecnologias como ferramentas que o apóiam no processo de reflexão e de construção do seu conhecimento.

Entre os pesquisadores da área já se discute a importância da "alfabetização tecnológica" como responsabilidade da escola e parte da resposta às questões ligadas à cidadania. Essa alfabetização não se restringe a um curso de informática, mas ao aprender a ler o mundo por meio dessa nova mídia. Nesse sentido, a informática deveria estar inserida em atividades essenciais do ambiente escolar, tais como aprender a ler, escrever, compreender textos, entender gráficos, contar, desenvolver noções espaciais, etc.

É importante rever os papéis desempenhados por esses atores, diante do novo contexto que se apresenta. É necessário que o professor tenha condições de refletir sobre essa nova realidade, repensar sua prática de ensino e construir novas formas de ação que permitam não só lidar com essa nova realidade, mas também construí-la.

O professor precisa se apropriar dessa tecnologia para ter condições de utilizá-la na sala de aula e no seu dia-a-dia. É necessário que ele tenha consciência de que ensinar e aprender continuará acontecendo por meio da palavra, do gesto, da emoção, da afetividade, dos textos lidos e escritos, da televisão, mas agora também pela informática, pela informação em tempo real, pela tela em camadas, em janelas que vão se tornando imprescindíveis para as interações sociais e o conhecimento do mundo que nos cerca.

A escola precisa mobilizar o seu corpo docente oferecendo condições para que ele se aproprie, dentro do processo de construção de sua competência, da utilização gradativa dos recursos informatizados. Somente a apropriação da utilização da tecnologia por parte do(a) professor(a) permitirá que ele/ela faça o uso adequado e eficiente na sua prática educacional. É necessário o entendimento de que muitos dos atuais professores estudaram em uma época em que a informática não fazia parte do dia-a-dia, e, entre os professores que estão em formação, poucos estão sendo preparados para mudar essa realidade.

Dessa forma, a responsabilidade das escolas e de seus gestores no encaminhamento da questão da informática na educação é indelegável e premente. A informática educacional deve fazer parte do projeto político pedagógico da escola. A articulação e o gerenciamento desse processo deve promover os recursos materiais necessários e a formação e capacitação dos recursos humanos, para que ocorra efetivamente uma educação informatizada que atenda aos interesses de uma sociedade que busca o desenvolvimento e que precisa se preparar para assumir o seu espaço como cidadã do mundo.

\section{Referências bibliográficas}

BARRETO, R. G. Formação de professores, tecnologias e linguagens. São Paulo: Loyola, 2002.

FRÓES, J. R. M. Relação e Informática: a relação homem/máquina e a questão da cognição. Disponível em: http://www.proinfo.gov.br/biblioteca/textos/txtie4doc.pdf 
GOUVÊA, S. F. Os caminhos do professor na era da tecnologia. Revista de Educação e Informática, 1999.

PALLOFF, R. M.; PRATT, K. Construindo comunidades de aprendizagem no ciberespaço: estratégias eficientes para salas de aula on-line. Porto Alegre: Artmed, 2002.

Carlos Eduardo Moreno Sampaio, mestre em Estatística e Métodos Quantitativos pela Universidade de Brasília (UnB), é coordenador-geral do Sistema Integrado de Informações Educacionais (SIEd) da Diretoria de Tratamento e Disseminação de Informações Educacionais (DTDIE/Inep/MEC).

Liliane Aranha Oliveira, doutoranda em Psicologia Social e do Trabalho e mestre em Estatística e Métodos Quantitativos pela Universidade de Brasília (UnB), é coordenadora de Análise Estatística da Coordenação-Geral do Sistema Integrado de Informações Educacionais (SIEd) da DTDIE/Inep/MEC.

Vanessa Nespoli, especialista em Estatística pela Universidade de Brasília (UnB), é consultora da Coordenação-Geral do SIEd da DTDIE/Inep/MEC.

\section{Abstract}

\section{Computer science as a support for the development of the process teaching-learning in basic education in Brazil}

This paper discusses that school access to the new information technologies will become a powerful instrument for the overcoming of chronic deficiencies of the Brazilian educational system, above all, in basic education. In this context, the educational process must be creative and flexible, propitiating the creation of learning environment that incorporates the new technologies, placing them in the service of the formation of critical and productive citizens. The creation of these new learning environments and their efficient action demand not only the implantation of an infrastructure of computer science laboratories, the use of the world-wide net of computers and learning applications, but above all, alterations in the role of the main actors of the teaching-learning process: the school, the teacher and the pupil.

Keywords: digital inclusion; access to the Internet in schools; pedagogical use of computer science; computerization of schools; school census. 


\section{Anexo}

Tabela 1 - Número de escolas de educação básica por condição de existência de computador, segundo as Unidades da Federação - Brasil 2004

\begin{tabular}{|c|c|c|c|c|c|c|c|c|c|}
\hline \multirow{3}{*}{$\begin{array}{l}\text { Unidade } \\
\text { Geográfica }\end{array}$} & \multicolumn{9}{|c|}{ Escolas de Educação Básica } \\
\hline & \multirow{2}{*}{ Total } & \multirow{2}{*}{ Pública } & \multirow{2}{*}{ Privada } & \multicolumn{3}{|c|}{ Com computador } & \multicolumn{3}{|c|}{ Sem computador } \\
\hline & & & & Total & Pública & Privada & Total & Pública & Privada \\
\hline Brasil & 210.094 & 174.894 & 35.200 & 77.859 & 51.927 & 25.932 & 132.235 & 122.967 & 9.268 \\
\hline Norte & 26.197 & 24.888 & 1.309 & 4.084 & 3.238 & 846 & 22.113 & 21.650 & 463 \\
\hline Rondônia & 2.292 & 2.090 & 202 & 610 & 451 & 159 & 1.682 & 1.639 & 43 \\
\hline Acre & 1.695 & 1.649 & 46 & 217 & 177 & 40 & 1.478 & 1.472 & 6 \\
\hline Amazonas & 5.156 & 4.872 & 284 & 876 & 666 & 210 & 4.280 & 4.206 & 74 \\
\hline Roraima & 789 & 770 & 19 & 143 & 131 & 12 & 646 & 639 & 7 \\
\hline Pará & 13.186 & 12.686 & 500 & 1.323 & 1.048 & 275 & 11.863 & 11.638 & 225 \\
\hline Amapá & 812 & 705 & 107 & 237 & 182 & 55 & 575 & 523 & 52 \\
\hline Tocantins & 2.267 & 2.116 & 151 & 678 & 583 & 95 & 1.589 & 1.533 & 56 \\
\hline Nordeste & 89.259 & 78.922 & 10.337 & 14.351 & 8.740 & 5.611 & 74.908 & 70.182 & 4.726 \\
\hline Maranhão & 13.940 & 13.021 & 919 & 1.347 & 1.037 & 310 & 12.593 & 11.984 & 609 \\
\hline Piauí & 7.966 & 7.442 & 524 & 648 & 351 & 297 & 7.318 & 7.091 & 227 \\
\hline Ceará & 12.983 & 10.911 & 2.072 & 2.762 & 1.657 & 1.105 & 10.221 & 9.254 & 967 \\
\hline $\begin{array}{l}\text { Rio Grande } \\
\text { do Norte }\end{array}$ & 4.588 & 3.988 & 600 & 863 & 501 & 362 & 3.725 & 3.487 & 238 \\
\hline Paraíba & 7.257 & 6.478 & 779 & 905 & 489 & 416 & 6.352 & 5.989 & 363 \\
\hline Pernambuco & 11.615 & 9.018 & 2.597 & 2.850 & 1.491 & 1.359 & 8.765 & 7.527 & 1.238 \\
\hline Alagoas & 3.708 & 3.366 & 342 & 406 & 215 & 191 & 3.302 & 3.151 & 151 \\
\hline Sergipe & 2.599 & 2.332 & 267 & 440 & 272 & 168 & 2.159 & 2.060 & 99 \\
\hline Bahia & 24.603 & 22.366 & 2.237 & 4.130 & 2.727 & 1.403 & 20.473 & 19.639 & 834 \\
\hline Sudeste & 57.553 & 41.026 & 16.527 & 36.532 & 22.748 & 13.784 & 21.021 & 18.278 & 2.743 \\
\hline Minas Gerais & 18.098 & 14.248 & 3.850 & 8.219 & 5.350 & 2.869 & 9.879 & 8.898 & 981 \\
\hline Espírito Santo & 4.139 & 3.637 & 502 & 1.415 & 960 & 455 & 2.724 & 2.677 & 47 \\
\hline Rio de Janeiro & 10.409 & 6.497 & 3.912 & 7.292 & 4.096 & 3.196 & 3.117 & 2.401 & 716 \\
\hline São Paulo & 24.907 & 16.644 & 8.263 & 19.606 & 12.342 & 7.264 & 5.301 & 4.302 & 999 \\
\hline Sul & 26.778 & 22.100 & 4.678 & 16.393 & 12.678 & 3.715 & 10.385 & 9.422 & 963 \\
\hline Paraná & 9.349 & 7.373 & 1.976 & 6.632 & 4.982 & 1.650 & 2.717 & 2.391 & 326 \\
\hline Santa Catarina & 6.803 & 5.790 & 1.013 & 3.889 & 3.084 & 805 & 2.914 & 2.706 & 208 \\
\hline $\begin{array}{l}\text { Rio Grande } \\
\text { do Sul }\end{array}$ & 10.626 & 8.937 & 1.689 & 5.872 & 4.612 & 1.260 & 4.754 & 4.325 & 429 \\
\hline Centro-Oeste & 10.307 & 7.958 & 2.349 & 6.499 & 4.523 & 1.976 & 3.808 & 3.435 & 373 \\
\hline $\begin{array}{l}\text { Mato Grosso } \\
\text { do Sul }\end{array}$ & 1.532 & 1.085 & 447 & 1.222 & 814 & 408 & 310 & 271 & 39 \\
\hline Mato Grosso & 2.967 & 2.643 & 324 & 1.452 & 1.181 & 271 & 1.515 & 1.462 & 53 \\
\hline Goiás & 4.762 & 3.618 & 1.144 & 2.805 & 1.920 & 885 & 1.957 & 1.698 & 259 \\
\hline Distrito Federal & 1.046 & 612 & 434 & 1.020 & 608 & 412 & 26 & 4 & 22 \\
\hline
\end{tabular}


Tabela 2 - Número de escolas de educação básica com computador por condição de existência de rede local, segundo as Unidades da Federação - Brasil 2004

\begin{tabular}{|c|c|c|c|c|c|c|c|c|c|}
\hline \multirow{3}{*}{$\begin{array}{l}\text { Unidade } \\
\text { Geográfica }\end{array}$} & \multicolumn{9}{|c|}{ Escolas de Educação Básica com computador } \\
\hline & \multirow{2}{*}{ Total } & \multirow{2}{*}{ Pública } & \multirow{2}{*}{ Privada } & \multicolumn{3}{|c|}{ Com rede local } & \multicolumn{3}{|c|}{ Sem rede local } \\
\hline & & & & Total & Pública & Privada & Total & Pública & Privada \\
\hline Brasil & 77.859 & 51.927 & 25.932 & 25.358 & 14.348 & 11.010 & 52.501 & 37.579 & 14.922 \\
\hline Norte & 4.084 & 3.238 & 846 & 1.058 & 682 & 376 & 3.026 & 2.556 & 470 \\
\hline Rondônia & 610 & 451 & 159 & 178 & 109 & 69 & 432 & 342 & 90 \\
\hline Acre & 217 & 177 & 40 & 49 & 29 & 20 & 168 & 148 & 20 \\
\hline Amazonas & 876 & 666 & 210 & 213 & 129 & 84 & 663 & 537 & 126 \\
\hline Roraima & 143 & 131 & 12 & 33 & 25 & 8 & 110 & 106 & 4 \\
\hline Pará & 1.323 & 1.048 & 275 & 343 & 212 & 131 & 980 & 836 & 144 \\
\hline Amapá & 237 & 182 & 55 & 67 & 44 & 23 & 170 & 138 & 32 \\
\hline Tocantins & 678 & 583 & 95 & 175 & 134 & 41 & 503 & 449 & 54 \\
\hline Nordeste & 14.351 & 8.740 & 5.611 & 4.309 & 2.265 & 2.044 & 10.042 & 6.475 & 3.567 \\
\hline Maranhão & 1.347 & 1.037 & 310 & 370 & 239 & 131 & 977 & 798 & 179 \\
\hline Piauí & 648 & 351 & 297 & 179 & 86 & 93 & 469 & 265 & 204 \\
\hline Ceará & 2.762 & 1.657 & 1.105 & 1.097 & 670 & 427 & 1.665 & 987 & 678 \\
\hline $\begin{array}{l}\text { Rio Grande } \\
\text { do Norte }\end{array}$ & 863 & 501 & 362 & 221 & 72 & 149 & 642 & 429 & 213 \\
\hline Paraíba & 905 & 489 & 416 & 234 & 96 & 138 & 671 & 393 & 278 \\
\hline Pernambuco & 2.850 & 1.491 & 1.359 & 941 & 486 & 455 & 1.909 & 1.005 & 904 \\
\hline Alagoas & 406 & 215 & 191 & 139 & 40 & 99 & 267 & 175 & 92 \\
\hline Sergipe & 440 & 272 & 168 & 128 & 51 & 77 & 312 & 221 & 91 \\
\hline Bahia & 4.130 & 2.727 & 1.403 & 1.000 & 525 & 475 & 3.130 & 2.202 & 928 \\
\hline Sudeste & 36.532 & 22.748 & 13.784 & 13.192 & 7.252 & 5.940 & 23.340 & 15.496 & 7.844 \\
\hline Minas Gerais & 8.219 & 5.350 & 2.869 & 2.556 & 1.479 & 1.077 & 5.663 & 3.871 & 1.792 \\
\hline Espírito Santo & 1.415 & 960 & 455 & 401 & 167 & 234 & 1.014 & 793 & 221 \\
\hline Rio de Janeiro & 7.292 & 4.096 & 3.196 & 2.491 & 1.161 & 1.330 & 4.801 & 2.935 & 1.866 \\
\hline São Paulo & 19.606 & 12.342 & 7.264 & 7.744 & 4.445 & 3.299 & 11.862 & 7.897 & 3.965 \\
\hline Sul & 16.393 & 12.678 & 3.715 & 4.783 & 3.127 & 1.656 & 11.610 & 9.551 & 2.059 \\
\hline Paraná & 6.632 & 4.982 & 1.650 & 1.649 & 1.028 & 621 & 4.983 & 3.954 & 1.029 \\
\hline Santa Catarina & 3.889 & 3.084 & 805 & 1.285 & 878 & 407 & 2.604 & 2.206 & 398 \\
\hline $\begin{array}{l}\text { Rio Grande } \\
\text { do Sul }\end{array}$ & 5.872 & 4.612 & 1.260 & 1.849 & 1.221 & 628 & 4.023 & 3.391 & 632 \\
\hline Centro-Oeste & 6.499 & 4.523 & 1.976 & 2.016 & 1.022 & 994 & 4.483 & 3.501 & 982 \\
\hline $\begin{array}{l}\text { Mato Grosso } \\
\text { do Sul }\end{array}$ & 1.222 & 814 & 408 & 423 & 214 & 209 & 799 & 600 & 199 \\
\hline Mato Grosso & 1.452 & 1.181 & 271 & 362 & 231 & 131 & 1.090 & 950 & 140 \\
\hline Goiás & 2.805 & 1.920 & 885 & 730 & 326 & 404 & 2.075 & 1.594 & 481 \\
\hline Distrito Federal & 1.020 & 608 & 412 & 501 & 251 & 250 & 519 & 357 & 162 \\
\hline
\end{tabular}


Tabela 3 - Número de escolas de educação básica com computador por condição de conexão à rede mundial de computadores, segundo as Unidades da Federação - Brasil 2004

\begin{tabular}{|c|c|c|c|c|c|c|c|c|c|}
\hline \multirow{3}{*}{$\begin{array}{l}\text { Unidade } \\
\text { Geográfica }\end{array}$} & \multicolumn{9}{|c|}{ Escolas de Educação Básica com computador } \\
\hline & \multirow{2}{*}{ Total } & \multirow{2}{*}{ Pública } & \multirow{2}{*}{ Privada } & \multicolumn{3}{|c|}{ Com Internet } & \multicolumn{3}{|c|}{ Sem Internet } \\
\hline & & & & Total & Pública & Privada & Total & Pública & Privada \\
\hline Brasil & 77.859 & 51.927 & 25.932 & 41.143 & 23.526 & 17.617 & 36.716 & 28.401 & 8.315 \\
\hline Norte & 4.084 & 3.238 & 846 & 1.298 & 750 & 548 & 2.786 & 2.488 & 298 \\
\hline Rondônia & 610 & 451 & 159 & 229 & 115 & 114 & 381 & 336 & 45 \\
\hline Acre & 217 & 177 & 40 & 54 & 24 & 30 & 163 & 153 & 10 \\
\hline Amazonas & 876 & 666 & 210 & 282 & 146 & 136 & 594 & 520 & 74 \\
\hline Roraima & 143 & 131 & 12 & 33 & 23 & 10 & 110 & 108 & 2 \\
\hline Pará & 1.323 & 1.048 & 275 & 369 & 204 & 165 & 954 & 844 & 110 \\
\hline Amapá & 237 & 182 & 55 & 81 & 48 & 33 & 156 & 134 & 22 \\
\hline Tocantins & 678 & 583 & 95 & 250 & 190 & 60 & 428 & 393 & 35 \\
\hline Nordeste & 14.351 & 8.740 & 5.611 & 6.086 & 3.137 & 2.949 & 8.265 & 5.603 & 2.662 \\
\hline Maranhão & 1.347 & 1.037 & 310 & 441 & 274 & 167 & 906 & 763 & 143 \\
\hline Piauí & 648 & 351 & 297 & 246 & 110 & 136 & 402 & 241 & 161 \\
\hline Ceará & 2.762 & 1.657 & 1.105 & 1.425 & 840 & 585 & 1.337 & 817 & 520 \\
\hline $\begin{array}{l}\text { Rio Grande } \\
\text { do Norte }\end{array}$ & 863 & 501 & 362 & 286 & 96 & 190 & 577 & 405 & 172 \\
\hline Paraíba & 905 & 489 & 416 & 342 & 119 & 223 & 563 & 370 & 193 \\
\hline Pernambuco & 2.850 & 1.491 & 1.359 & 1.553 & 880 & 673 & 1.297 & 611 & 686 \\
\hline Alagoas & 406 & 215 & 191 & 189 & 63 & 126 & 217 & 152 & 65 \\
\hline Sergipe & 440 & 272 & 168 & 133 & 47 & 86 & 307 & 225 & 82 \\
\hline Bahia & 4.130 & 2.727 & 1.403 & 1.471 & 708 & 763 & 2.659 & 2.019 & 640 \\
\hline Sudeste & 36.532 & 22.748 & 13.784 & 24.289 & 14.171 & 10.118 & 12.243 & 8.577 & 3.666 \\
\hline Minas Gerais & 8.219 & 5.350 & 2.869 & 2.926 & 1.192 & 1.734 & 5.293 & 4.158 & 1.135 \\
\hline Espírito Santo & 1.415 & 960 & 455 & 514 & 189 & 325 & 901 & 771 & 130 \\
\hline Rio de Janeiro & 7.292 & 4.096 & 3.196 & 4.297 & 2.217 & 2.080 & 2.995 & 1.879 & 1.116 \\
\hline São Paulo & 19.606 & 12.342 & 7.264 & 16.552 & 10.573 & 5.979 & 3.054 & 1.769 & 1.285 \\
\hline Sul & 16.393 & 12.678 & 3.715 & 6.721 & 4.065 & 2.656 & 9.672 & 8.613 & 1.059 \\
\hline Paraná & 6.632 & 4.982 & 1.650 & 2.971 & 1.840 & 1.131 & 3.661 & 3.142 & 519 \\
\hline Santa Catarina & 3.889 & 3.084 & 805 & 1.630 & 1.059 & 571 & 2.259 & 2.025 & 234 \\
\hline $\begin{array}{l}\text { Rio Grande } \\
\text { do Sul }\end{array}$ & 5.872 & 4.612 & 1.260 & 2.120 & 1.166 & 954 & 3.752 & 3.446 & 306 \\
\hline Centro-Oeste & 6.499 & 4.523 & 1.976 & 2.749 & 1.403 & 1.346 & 3.750 & 3.120 & 630 \\
\hline $\begin{array}{l}\text { Mato Grosso } \\
\text { do Sul }\end{array}$ & 1.222 & 814 & 408 & 573 & 273 & 300 & 649 & 541 & 108 \\
\hline Mato Grosso & 1.452 & 1.181 & 271 & 528 & 338 & 190 & 924 & 843 & 81 \\
\hline Goiás & 2.805 & 1.920 & 885 & 791 & 263 & 528 & 2.014 & 1.657 & 357 \\
\hline Distrito Federal & 1.020 & 608 & 412 & 857 & 529 & 328 & 163 & 79 & 84 \\
\hline
\end{tabular}


Tabela 4 - Número de escolas de educação básica com computador por condição de utilização pedagógica da informática, segundo as Unidades

da Federação - Brasil 2004

\begin{tabular}{|c|c|c|c|c|c|c|c|c|c|}
\hline \multirow{3}{*}{$\begin{array}{l}\text { Unidade } \\
\text { Geográfica }\end{array}$} & \multicolumn{9}{|c|}{ Escolas de Educação Básica com computador } \\
\hline & \multirow{2}{*}{ Total } & \multirow{2}{*}{ Pública } & \multirow{2}{*}{ Privada } & \multicolumn{3}{|c|}{ Com uso pedagógico } & \multicolumn{3}{|c|}{ Sem uso pedagógico } \\
\hline & & & & Total & Pública & Privada & Total & Pública & Privada \\
\hline Brasil & 77.859 & 51.927 & 25.932 & 46.448 & 27.205 & 19.243 & 31.381 & 24.697 & 6.684 \\
\hline Norte & 4.084 & 3.238 & 846 & 2.128 & 1.534 & 594 & 1.951 & 1.700 & 251 \\
\hline Rondônia & 610 & 451 & 159 & 328 & 211 & 117 & 280 & 238 & 42 \\
\hline Acre & 217 & 177 & 40 & 99 & 67 & 32 & 117 & 109 & 8 \\
\hline Amazonas & 876 & 666 & 210 & 327 & 183 & 144 & 549 & 483 & 66 \\
\hline Roraima & 143 & 131 & 12 & 79 & 70 & 9 & 64 & 61 & 3 \\
\hline Pará & 1.323 & 1.048 & 275 & 660 & 465 & 195 & 661 & 582 & 79 \\
\hline Amapá & 237 & 182 & 55 & 99 & 68 & 31 & 138 & 114 & 24 \\
\hline Tocantins & 678 & 583 & 95 & 536 & 470 & 66 & 142 & 113 & 29 \\
\hline Nordeste & 14.351 & 8.740 & 5.611 & 8.441 & 4.400 & 4.041 & 5.897 & 4.330 & 1.567 \\
\hline Maranhão & 1.347 & 1.037 & 310 & 596 & 370 & 226 & 749 & 665 & 84 \\
\hline Piauí & 648 & 351 & 297 & 354 & 172 & 182 & 294 & 179 & 115 \\
\hline Ceará & 2.762 & 1.657 & 1.105 & 1.921 & 1.076 & 845 & 840 & 581 & 259 \\
\hline $\begin{array}{l}\text { Rio Grande } \\
\text { do Norte }\end{array}$ & 863 & 501 & 362 & 512 & 231 & 281 & 351 & 270 & 81 \\
\hline Paraíba & 905 & 489 & 416 & 524 & 240 & 284 & 380 & 248 & 132 \\
\hline Pernambuco & 2.850 & 1.491 & 1.359 & 1.818 & 774 & 1.044 & 1.032 & 717 & 315 \\
\hline Alagoas & 406 & 215 & 191 & 243 & 104 & 139 & 163 & 111 & 52 \\
\hline Sergipe & 440 & 272 & 168 & 216 & 109 & 107 & 224 & 163 & 61 \\
\hline Bahia & 4.130 & 2.727 & 1.403 & 2.257 & 1.324 & 933 & 1.864 & 1.396 & 468 \\
\hline Sudeste & 36.532 & 22.748 & 13.784 & 22.662 & 12.224 & 10.438 & 13.867 & 10.521 & 3.346 \\
\hline Minas Gerais & 8.219 & 5.350 & 2.869 & 4.326 & 2.402 & 1.924 & 3.893 & 2.948 & 945 \\
\hline Espírito Santo & 1.415 & 960 & 455 & 845 & 474 & 371 & 570 & 486 & 84 \\
\hline Rio de Janeiro & 7.292 & 4.096 & 3.196 & 4.521 & 1.933 & 2.588 & 2.771 & 2.163 & 608 \\
\hline São Paulo & 19.606 & 12.342 & 7.264 & 12.970 & 7.415 & 5.555 & 6.633 & 4.924 & 1.709 \\
\hline Sul & 16.393 & 12.678 & 3.715 & 9.718 & 7.000 & 2.718 & 6.670 & 5.674 & 996 \\
\hline Paraná & 6.632 & 4.982 & 1.650 & 3.625 & 2.507 & 1.118 & 3.005 & 2.473 & 532 \\
\hline Santa Catarina & 3.889 & 3.084 & 805 & 2.725 & 2.098 & 627 & 1.164 & 986 & 178 \\
\hline $\begin{array}{l}\text { Rio Grande } \\
\text { do Sul }\end{array}$ & 5.872 & 4.612 & 1.260 & 3.368 & 2.395 & 973 & 2.501 & 2.215 & 286 \\
\hline Centro-Oeste & 6.499 & 4.523 & 1.976 & 3.499 & 2.047 & 1.452 & 2.996 & 2.472 & 524 \\
\hline $\begin{array}{l}\text { Mato Grosso } \\
\text { do Sul }\end{array}$ & 1.222 & 814 & 408 & 836 & 514 & 322 & 386 & 300 & 86 \\
\hline Mato Grosso & 1.452 & 1.181 & 271 & 877 & 680 & 197 & 571 & 497 & 74 \\
\hline Goiás & 2.805 & 1.920 & 885 & 1.273 & 673 & 600 & 1.532 & 1.247 & 285 \\
\hline Distrito Federal & 1.020 & 608 & 412 & 513 & 180 & 333 & 507 & 428 & 79 \\
\hline
\end{tabular}

Fonte: MEC/Inep

Nota: 30 escolas não declararam o tipo de utilização que fazem do computador. 
Tabela 5 - Número de escolas de educação básica com computador, conexão à Internet e que fazem uso pedagógico da informática, segundo as Unidades

da Federação - Brasil 2004

\begin{tabular}{|c|c|c|c|c|c|c|c|c|c|}
\hline \multirow{3}{*}{$\begin{array}{l}\text { Unidade } \\
\text { Geográfica }\end{array}$} & \multicolumn{9}{|c|}{ Escolas de Educação Básica } \\
\hline & \multirow{2}{*}{ Total } & \multirow{2}{*}{ Pública } & \multirow{2}{*}{ Privada } & \multicolumn{3}{|c|}{ Com computador } & \multicolumn{3}{|c|}{ Com Internet e uso pedagógico } \\
\hline & & & & Total & Pública & Privada & Total & Pública & Privada \\
\hline Brasil & 210.094 & 174.894 & 35.200 & 77.859 & 51.927 & 25.932 & 30.602 & 15.911 & 14.691 \\
\hline Norte & 26.197 & 24.888 & 1.309 & 4.084 & 3.238 & 846 & 1.036 & 584 & 452 \\
\hline Rondônia & 2.292 & 2.090 & 202 & 610 & 451 & 159 & 179 & 83 & 96 \\
\hline Acre & 1.695 & 1.649 & 46 & 217 & 177 & 40 & 48 & 21 & 27 \\
\hline Amazonas & 5.156 & 4.872 & 284 & 876 & 666 & 210 & 183 & 74 & 109 \\
\hline Roraima & 789 & 770 & 19 & 143 & 131 & 12 & 31 & 23 & 8 \\
\hline Pará & 13.186 & 12.686 & 500 & 1.323 & 1.048 & 275 & 314 & 175 & 139 \\
\hline Amapá & 812 & 705 & 107 & 237 & 182 & 55 & 60 & 37 & 23 \\
\hline Tocantins & 2.267 & 2.116 & 151 & 678 & 583 & 95 & 221 & 171 & 50 \\
\hline Nordeste & 89.259 & 78.922 & 10.337 & 14.351 & 8.740 & 5.611 & 4.910 & 2.413 & 2.497 \\
\hline Maranhão & 13.940 & 13.021 & 919 & 1.347 & 1.037 & 310 & 365 & 213 & 152 \\
\hline Piauí & 7.966 & 7.442 & 524 & 648 & 351 & 297 & 189 & 85 & 104 \\
\hline Ceará & 12.983 & 10.911 & 2.072 & 2.762 & 1.657 & 1.105 & 1.250 & 748 & 502 \\
\hline $\begin{array}{l}\text { Rio Grande } \\
\text { do Norte }\end{array}$ & 4.588 & 3.988 & 600 & 863 & 501 & 362 & 247 & 82 & 165 \\
\hline Paraíba & 7.257 & 6.478 & 779 & 905 & 489 & 416 & 269 & 90 & 179 \\
\hline Pernambuco & 11.615 & 9.018 & 2.597 & 2.850 & 1.491 & 1.359 & 1.142 & 554 & 588 \\
\hline Alagoas & 3.708 & 3.366 & 342 & 406 & 215 & 191 & 162 & 54 & 108 \\
\hline Sergipe & 2.599 & 2.332 & 267 & 440 & 272 & 168 & 107 & 36 & 71 \\
\hline Bahia & 24.603 & 22.366 & 2.237 & 4.130 & 2.727 & 1.403 & 1.179 & 551 & 628 \\
\hline Sudeste & 57.553 & 41.026 & 16.527 & 36.532 & 22.748 & 13.784 & 17.463 & 9.050 & 8.413 \\
\hline Minas Gerais & 18.098 & 14.248 & 3.850 & 8.219 & 5.350 & 2.869 & 2.221 & 837 & 1.384 \\
\hline Espírito Santo & 4.139 & 3.637 & 502 & 1.415 & 960 & 455 & 456 & 166 & 290 \\
\hline Rio de Janeiro & 10.409 & 6.497 & 3.912 & 7.292 & 4.096 & 3.196 & 3.079 & 1.237 & 1.842 \\
\hline São Paulo & 24.907 & 16.644 & 8.263 & 19.606 & 12.342 & 7.264 & 11.707 & 6.810 & 4.897 \\
\hline Sul & 26.778 & 22.100 & 4.678 & 16.393 & 12.678 & 3.715 & 5.182 & 2.987 & 2.195 \\
\hline Paraná & 9.349 & 7.373 & 1.976 & 6.632 & 4.982 & 1.650 & 2.109 & 1.225 & 884 \\
\hline Santa Catarina & 6.803 & 5.790 & 1.013 & 3.889 & 3.084 & 805 & 1.402 & 900 & 502 \\
\hline $\begin{array}{l}\text { Rio Grande } \\
\text { do Sul }\end{array}$ & 10.626 & 8.937 & 1.689 & 5.872 & 4.612 & 1.260 & 1.671 & 862 & 809 \\
\hline Centro-Oeste & 10.307 & 7.958 & 2.349 & 6.499 & 4.523 & 1.976 & 2.011 & 877 & 1.134 \\
\hline $\begin{array}{l}\text { Mato Grosso } \\
\text { do Sul }\end{array}$ & 1.532 & 1.085 & 447 & 1.222 & 814 & 408 & 483 & 221 & 262 \\
\hline Mato Grosso & 2.967 & 2.643 & 324 & 1.452 & 1.181 & 271 & 411 & 251 & 160 \\
\hline Goiás & 4.762 & 3.618 & 1.144 & 2.805 & 1.920 & 885 & 656 & 230 & 426 \\
\hline Distrito Federal & 1.046 & 612 & 434 & 1.020 & 608 & 412 & 461 & 175 & 286 \\
\hline
\end{tabular}


Tabela 6 - Número de escolas de educação básica com computador, rede local, conexão à Internet e que fazem uso pedagógico da informática, segundo as Unidades da Federação - Brasil 2004

\begin{tabular}{|c|c|c|c|c|c|c|c|c|c|}
\hline \multirow{3}{*}{$\begin{array}{l}\text { Unidade } \\
\text { Geográfica }\end{array}$} & \multicolumn{9}{|c|}{ Escolas de Educação Básica } \\
\hline & \multirow{2}{*}{ Total } & \multirow{2}{*}{ Pública } & \multirow{2}{*}{ Privada } & \multicolumn{3}{|c|}{ Com computador } & \multicolumn{3}{|c|}{$\begin{array}{l}\text { Com rede, Internet } \\
\text { e uso pedagógico }\end{array}$} \\
\hline & & & & Total & Pública & Privada & Total & Pública & Privada \\
\hline Brasil & 210.094 & 174.894 & 35.200 & 77.859 & 51.927 & 25.932 & 19.253 & 9.772 & 9.481 \\
\hline Norte & 26.197 & 24.888 & 1.309 & 4.084 & 3.238 & 846 & 737 & 415 & 322 \\
\hline Rondônia & 2.292 & 2.090 & 202 & 610 & 451 & 159 & 115 & 53 & 62 \\
\hline Acre & 1.695 & 1.649 & 46 & 217 & 177 & 40 & 33 & 13 & 20 \\
\hline Amazonas & 5.156 & 4.872 & 284 & 876 & 666 & 210 & 124 & 55 & 69 \\
\hline Roraima & 789 & 770 & 19 & 143 & 131 & 12 & 27 & 20 & 7 \\
\hline Pará & 13.186 & 12.686 & 500 & 1.323 & 1.048 & 275 & 253 & 143 & 110 \\
\hline Amapá & 812 & 705 & 107 & 237 & 182 & 55 & 47 & 30 & 17 \\
\hline Tocantins & 2.267 & 2.116 & 151 & 678 & 583 & 95 & 138 & 101 & 37 \\
\hline Nordeste & 89.259 & 78.922 & 10.337 & 14.351 & 8.740 & 5.611 & 3.240 & 1.665 & 1.575 \\
\hline Maranhão & 13.940 & 13.021 & 919 & 1.347 & 1.037 & 310 & 249 & 145 & 104 \\
\hline Piauí & 7.966 & 7.442 & 524 & 648 & 351 & 297 & 120 & 55 & 65 \\
\hline Ceará & 12.983 & 10.911 & 2.072 & 2.762 & 1.657 & 1.105 & 903 & 588 & 315 \\
\hline $\begin{array}{l}\text { Rio Grande } \\
\text { do Norte }\end{array}$ & 4.588 & 3.988 & 600 & 863 & 501 & 362 & 171 & 51 & 120 \\
\hline Paraíba & 7.257 & 6.478 & 779 & 905 & 489 & 416 & 168 & 63 & 105 \\
\hline Pernambuco & 11.615 & 9.018 & 2.597 & 2.850 & 1.491 & 1.359 & 726 & 371 & 355 \\
\hline Alagoas & 3.708 & 3.366 & 342 & 406 & 215 & 191 & 115 & 34 & 81 \\
\hline Sergipe & 2.599 & 2.332 & 267 & 440 & 272 & 168 & 89 & 31 & 58 \\
\hline Bahia & 24.603 & 22.366 & 2.237 & 4.130 & 2.727 & 1.403 & 699 & 327 & 372 \\
\hline Sudeste & 57.553 & 41.026 & 16.527 & 36.532 & 22.748 & 13.784 & 10.475 & 5.209 & 5.266 \\
\hline Minas Gerais & 18.098 & 14.248 & 3.850 & 8.219 & 5.350 & 2.869 & 1.471 & 565 & 906 \\
\hline Espírito Santo & 4.139 & 3.637 & 502 & 1.415 & 960 & 455 & 314 & 106 & 208 \\
\hline Rio de Janeiro & 10.409 & 6.497 & 3.912 & 7.292 & 4.096 & 3.196 & 1.764 & 658 & 1.106 \\
\hline São Paulo & 24.907 & 16.644 & 8.263 & 19.606 & 12.342 & 7.264 & 6.926 & 3.880 & 3.046 \\
\hline Sul & 26.778 & 22.100 & 4.678 & 16.393 & 12.678 & 3.715 & 3.388 & 1.898 & 1.490 \\
\hline Paraná & 9.349 & 7.373 & 1.976 & 6.632 & 4.982 & 1.650 & 1.231 & 677 & 554 \\
\hline Santa Catarina & 6.803 & 5.790 & 1.013 & 3.889 & 3.084 & 805 & 999 & 628 & 371 \\
\hline $\begin{array}{l}\text { Rio Grande } \\
\text { do Sul }\end{array}$ & 10.626 & 8.937 & 1.689 & 5.872 & 4.612 & 1.260 & 1.158 & 593 & 565 \\
\hline Centro-Oeste & 10.307 & 7.958 & 2.349 & 6.499 & 4.523 & 1.976 & 1.413 & 585 & 828 \\
\hline $\begin{array}{l}\text { Mato Grosso } \\
\text { do Sul }\end{array}$ & 1.532 & 1.085 & 447 & 1.222 & 814 & 408 & 332 & 147 & 185 \\
\hline Mato Grosso & 2.967 & 2.643 & 324 & 1.452 & 1.181 & 271 & 250 & 139 & 111 \\
\hline Goiás & 4.762 & 3.618 & 1.144 & 2.805 & 1.920 & 885 & 498 & 190 & 308 \\
\hline Distrito Federal & 1.046 & 612 & 434 & 1.020 & 608 & 412 & 333 & 109 & 224 \\
\hline
\end{tabular}

Fonte: MEC/Inep 
Tabela 7 - Número de escolas de educação básica com computador, conexão à Internet e que não fazem uso pedagógico da informática, segundo as Unidades da Federação - Brasil 2004

\begin{tabular}{|c|c|c|c|c|c|c|c|c|c|}
\hline \multirow{3}{*}{$\begin{array}{l}\text { Unidade } \\
\text { Geográfica }\end{array}$} & \multicolumn{9}{|c|}{ Escolas de Educação Básica } \\
\hline & \multirow{2}{*}{ Total } & \multirow{2}{*}{ Pública } & \multirow{2}{*}{ Privada } & \multicolumn{3}{|c|}{ Com computador } & \multicolumn{3}{|c|}{$\begin{array}{c}\text { Com Internet } \\
\text { e sem uso pedagógico }\end{array}$} \\
\hline & & & & Total & Pública & Privada & Total & Pública & Privada \\
\hline Brasil & 210.094 & 174.894 & 35.200 & 77.859 & 51.927 & 25.932 & 10.533 & 7.608 & 2.925 \\
\hline Norte & 26.197 & 24.888 & 1.309 & 4.084 & 3.238 & 846 & 260 & 164 & 96 \\
\hline Rondônia & 2.292 & 2.090 & 202 & 610 & 451 & 159 & 49 & 31 & 18 \\
\hline Acre & 1.695 & 1.649 & 46 & 217 & 177 & 40 & 6 & 3 & 3 \\
\hline Amazonas & 5.156 & 4.872 & 284 & 876 & 666 & 210 & 99 & 72 & 27 \\
\hline Roraima & 789 & 770 & 19 & 143 & 131 & 12 & 2 & 0 & 2 \\
\hline Pará & 13.186 & 12.686 & 500 & 1.323 & 1.048 & 275 & 54 & 28 & 26 \\
\hline Amapá & 812 & 705 & 107 & 237 & 182 & 55 & 21 & 11 & 10 \\
\hline Tocantins & 2.267 & 2.116 & 151 & 678 & 583 & 95 & 29 & 19 & 10 \\
\hline Nordeste & 89.259 & 78.922 & 10.337 & 14.351 & 8.740 & 5.611 & 1.175 & 724 & 451 \\
\hline Maranhão & 13.940 & 13.021 & 919 & 1.347 & 1.037 & 310 & 76 & 61 & 15 \\
\hline Piauí & 7.966 & 7.442 & 524 & 648 & 351 & 297 & 57 & 25 & 32 \\
\hline Ceará & 12.983 & 10.911 & 2.072 & 2.762 & 1.657 & 1.105 & 174 & 92 & 82 \\
\hline $\begin{array}{l}\text { Rio Grande } \\
\text { do Norte }\end{array}$ & 4.588 & 3.988 & 600 & 863 & 501 & 362 & 39 & 14 & 25 \\
\hline Paraíba & 7.257 & 6.478 & 779 & 905 & 489 & 416 & 73 & 29 & 44 \\
\hline Pernambuco & 11.615 & 9.018 & 2.597 & 2.850 & 1.491 & 1.359 & 411 & 326 & 85 \\
\hline Alagoas & 3.708 & 3.366 & 342 & 406 & 215 & 191 & 27 & 9 & 18 \\
\hline Sergipe & 2.599 & 2.332 & 267 & 440 & 272 & 168 & 26 & 11 & 15 \\
\hline Bahia & 24.603 & 22.366 & 2.237 & 4.130 & 2.727 & 1.403 & 292 & 157 & 135 \\
\hline Sudeste & 57.553 & 41.026 & 16.527 & 36.532 & 22.748 & 13.784 & 6.823 & 5.118 & 1.705 \\
\hline Minas Gerais & 18.098 & 14.248 & 3.850 & 8.219 & 5.350 & 2.869 & 705 & 355 & 350 \\
\hline Espírito Santo & 4.139 & 3.637 & 502 & 1.415 & 960 & 455 & 58 & 23 & 35 \\
\hline Rio de Janeiro & 10.409 & 6.497 & 3.912 & 7.292 & 4.096 & 3.196 & 1.218 & 980 & 238 \\
\hline São Paulo & 24.907 & 16.644 & 8.263 & 19.606 & 12.342 & 7.264 & 4.842 & 3.760 & 1.082 \\
\hline Sul & 26.778 & 22.100 & 4.678 & 16.393 & 12.678 & 3.715 & 1.539 & 1.078 & 461 \\
\hline Paraná & 9.349 & 7.373 & 1.976 & 6.632 & 4.982 & 1.650 & 862 & 615 & 247 \\
\hline Santa Catarina & 6.803 & 5.790 & 1.013 & 3.889 & 3.084 & 805 & 228 & 159 & 69 \\
\hline $\begin{array}{l}\text { Rio Grande } \\
\text { do Sul }\end{array}$ & 10.626 & 8.937 & 1.689 & 5.872 & 4.612 & 1.260 & 449 & 304 & 145 \\
\hline Centro-Oeste & 10.307 & 7.958 & 2.349 & 6.499 & 4.523 & 1.976 & 736 & 524 & 212 \\
\hline $\begin{array}{l}\text { Mato Grosso } \\
\text { do Sul }\end{array}$ & 1.532 & 1.085 & 447 & 1.222 & 814 & 408 & 90 & 52 & 38 \\
\hline Mato Grosso & 2.967 & 2.643 & 324 & 1.452 & 1.181 & 271 & 115 & 85 & 30 \\
\hline Goiás & 4.762 & 3.618 & 1.144 & 2.805 & 1.920 & 885 & 135 & 33 & 102 \\
\hline Distrito Federal & 1.046 & 612 & 434 & 1.020 & 608 & 412 & 396 & 354 & 42 \\
\hline
\end{tabular}


Tabela 8 - Número de escolas de educação básica com computador, rede local, conexão à Internet e que não fazem uso pedagógico da informática, segundo as

Unidades da Federação - Brasil 2004

\begin{tabular}{|c|c|c|c|c|c|c|c|c|c|}
\hline \multirow{3}{*}{$\begin{array}{l}\text { Unidade } \\
\text { Geográfica }\end{array}$} & \multicolumn{9}{|c|}{ Escolas de Educação Básica } \\
\hline & \multirow{2}{*}{ Total } & \multirow{2}{*}{ Pública } & \multirow{2}{*}{ Privada } & \multicolumn{3}{|c|}{ Com computador } & \multicolumn{3}{|c|}{$\begin{array}{l}\text { Com rede, Internet } \\
\text { e sem uso pedagógico }\end{array}$} \\
\hline & & & & Total & Pública & Privada & Total & Pública & Privada \\
\hline Brasil & 210.094 & 174.894 & 35.200 & 77.859 & 51.927 & 25.932 & 2.145 & 1.538 & 607 \\
\hline Norte & 26.197 & 24.888 & 1.309 & 4.084 & 3.238 & 846 & 72 & 51 & 21 \\
\hline Rondônia & 2.292 & 2.090 & 202 & 610 & 451 & 159 & 16 & 12 & 4 \\
\hline Acre & 1.695 & 1.649 & 46 & 217 & 177 & 40 & 2 & 2 & 0 \\
\hline Amazonas & 5.156 & 4.872 & 284 & 876 & 666 & 210 & 31 & 27 & 4 \\
\hline Roraima & 789 & 770 & 19 & 143 & 131 & 12 & 1 & 0 & 1 \\
\hline Pará & 13.186 & 12.686 & 500 & 1.323 & 1.048 & 275 & 12 & 5 & 7 \\
\hline Amapá & 812 & 705 & 107 & 237 & 182 & 55 & 6 & 3 & 3 \\
\hline Tocantins & 2.267 & 2.116 & 151 & 678 & 583 & 95 & 4 & 2 & 2 \\
\hline Nordeste & 89.259 & 78.922 & 10.337 & 14.351 & 8.740 & 5.611 & 273 & 160 & 113 \\
\hline Maranhão & 13.940 & 13.021 & 919 & 1.347 & 1.037 & 310 & 33 & 26 & 7 \\
\hline Piauí & 7.966 & 7.442 & 524 & 648 & 351 & 297 & 14 & 5 & 9 \\
\hline Ceará & 12.983 & 10.911 & 2.072 & 2.762 & 1.657 & 1.105 & 56 & 37 & 19 \\
\hline $\begin{array}{l}\text { Rio Grande } \\
\text { do Norte }\end{array}$ & 4.588 & 3.988 & 600 & 863 & 501 & 362 & 6 & 2 & 4 \\
\hline Paraíba & 7.257 & 6.478 & 779 & 905 & 489 & 416 & 15 & 6 & 9 \\
\hline Pernambuco & 11.615 & 9.018 & 2.597 & 2.850 & 1.491 & 1.359 & 73 & 56 & 17 \\
\hline Alagoas & 3.708 & 3.366 & 342 & 406 & 215 & 191 & 5 & 0 & 5 \\
\hline Sergipe & 2.599 & 2.332 & 267 & 440 & 272 & 168 & 7 & 1 & 6 \\
\hline Bahia & 24.603 & 22.366 & 2.237 & 4.130 & 2.727 & 1.403 & 64 & 27 & 37 \\
\hline Sudeste & 57.553 & 41.026 & 16.527 & 36.532 & 22.748 & 13.784 & 1.252 & 939 & 313 \\
\hline Minas Gerais & 18.098 & 14.248 & 3.850 & 8.219 & 5.350 & 2.869 & 187 & 109 & 78 \\
\hline Espírito Santo & 4.139 & 3.637 & 502 & 1.415 & 960 & 455 & 9 & 2 & 7 \\
\hline Rio de Janeiro & 10.409 & 6.497 & 3.912 & 7.292 & 4.096 & 3.196 & 395 & 348 & 47 \\
\hline São Paulo & 24.907 & 16.644 & 8.263 & 19.606 & 12.342 & 7.264 & 661 & 480 & 181 \\
\hline Sul & 26.778 & 22.100 & 4.678 & 16.393 & 12.678 & 3.715 & 299 & 217 & 82 \\
\hline Paraná & 9.349 & 7.373 & 1.976 & 6.632 & 4.982 & 1.650 & 144 & 112 & 32 \\
\hline Santa Catarina & 6.803 & 5.790 & 1.013 & 3.889 & 3.084 & 805 & 39 & 27 & 12 \\
\hline $\begin{array}{l}\text { Rio Grande } \\
\text { do Sul }\end{array}$ & 10.626 & 8.937 & 1.689 & 5.872 & 4.612 & 1.260 & 116 & 78 & 38 \\
\hline Centro-Oeste & 10.307 & 7.958 & 2.349 & 6.499 & 4.523 & 1.976 & 249 & 171 & 78 \\
\hline $\begin{array}{l}\text { Mato Grosso } \\
\text { do Sul }\end{array}$ & 1.532 & 1.085 & 447 & 1.222 & 814 & 408 & 17 & 6 & 11 \\
\hline Mato Grosso & 2.967 & 2.643 & 324 & 1.452 & 1.181 & 271 & 31 & 17 & 14 \\
\hline Goiás & 4.762 & 3.618 & 1.144 & 2.805 & 1.920 & 885 & 49 & 11 & 38 \\
\hline Distrito Federal & 1.046 & 612 & 434 & 1.020 & 608 & 412 & 152 & 137 & 15 \\
\hline
\end{tabular}


Tabela 9 - Número de escolas de educação básica que fazem utilização pedagógica da informática por local de utilização, segundo as Unidades da Federação - Brasil 2004

(continua)

\begin{tabular}{|c|c|c|c|c|c|c|}
\hline \multirow{2}{*}{$\begin{array}{l}\text { Unidade } \\
\text { Geográfica }\end{array}$} & \multicolumn{6}{|c|}{ Onde estão sendo usados os microcomputadores } \\
\hline & $\begin{array}{l}\text { Dependência } \\
\text { Administrativa }\end{array}$ & $\begin{array}{l}\text { Em laboratórios, } \\
\text { salas de informática }\end{array}$ & $\begin{array}{l}\text { Em salas } \\
\text { de aula }\end{array}$ & Em Biblioteca & $\begin{array}{l}\text { Em sala de } \\
\text { professores }\end{array}$ & $\begin{array}{l}\text { Em outros } \\
\text { locais }\end{array}$ \\
\hline \multirow{3}{*}{ Brasil } & Total & 27.168 & 3.084 & 7.541 & 9.614 & 19.787 \\
\hline & Pública & 14.523 & 1.173 & 3.225 & 6.146 & 11.830 \\
\hline & Privada & 12.645 & 1.911 & 4.316 & 3.468 & 7.957 \\
\hline \multirow{3}{*}{ Norte } & Total & 1.009 & 69 & 291 & 591 & 1.081 \\
\hline & Pública & 630 & 26 & 147 & 453 & 795 \\
\hline & Privada & 379 & 43 & 144 & 138 & 286 \\
\hline \multirow{3}{*}{ Rondônia } & Total & 104 & 5 & 31 & 114 & 181 \\
\hline & Pública & 46 & 3 & 8 & 81 & 119 \\
\hline & Privada & 58 & 2 & 23 & 33 & 62 \\
\hline \multirow{3}{*}{ Acre } & Total & 59 & 3 & 11 & 16 & 40 \\
\hline & Pública & 36 & 0 & 2 & 10 & 30 \\
\hline & Privada & 23 & 3 & 9 & 6 & 10 \\
\hline \multirow{3}{*}{ Amazonas } & Total & 233 & 8 & 47 & 90 & 124 \\
\hline & Pública & 112 & 1 & 11 & 55 & 71 \\
\hline & Privada & 121 & 7 & 36 & 35 & 53 \\
\hline \multirow{3}{*}{ Roraima } & Total & 36 & 3 & 9 & 32 & 49 \\
\hline & Pública & 29 & 2 & 5 & 28 & 43 \\
\hline & Privada & 7 & 1 & 4 & 4 & 6 \\
\hline \multirow{3}{*}{ Pará } & Total & 396 & 33 & 71 & 96 & 291 \\
\hline & Pública & 279 & 8 & 22 & 62 & 182 \\
\hline & Privada & 117 & 25 & 49 & 34 & 109 \\
\hline \multirow{3}{*}{ Amapá } & Total & 61 & 3 & 13 & 24 & 43 \\
\hline & Pública & 41 & 1 & 4 & 12 & 33 \\
\hline & Privada & 20 & 2 & 9 & 12 & 10 \\
\hline \multirow{3}{*}{ Tocantins } & Total & 120 & 14 & 109 & 219 & 353 \\
\hline & Pública & 87 & 11 & 95 & 205 & 317 \\
\hline & Privada & 33 & 3 & 14 & 14 & 36 \\
\hline \multirow{3}{*}{ Nordeste } & Total & 4.641 & 404 & 1.388 & 1.492 & 4.001 \\
\hline & Pública & 2.198 & 123 & 653 & 935 & 2.231 \\
\hline & Privada & 2.443 & 281 & 735 & 557 & 1.770 \\
\hline \multirow{3}{*}{ Maranhão } & Total & 363 & 26 & 74 & 61 & 233 \\
\hline & Pública & 208 & 10 & 27 & 32 & 147 \\
\hline & Privada & 155 & 16 & 47 & 29 & 86 \\
\hline \multirow{3}{*}{ Piauí } & Total & 211 & 12 & 49 & 44 & 139 \\
\hline & Pública & 105 & 7 & 13 & 12 & 69 \\
\hline & Privada & 106 & 5 & 36 & 32 & 70 \\
\hline \multirow{3}{*}{ Ceará } & Total & 1.039 & 61 & 566 & 419 & 901 \\
\hline & Pública & 477 & 25 & 415 & 343 & 536 \\
\hline & Privada & 562 & 36 & 151 & 76 & 365 \\
\hline
\end{tabular}


Tabela 9 - Número de escolas de educação básica que fazem utilização pedagógica da informática por local de utilização, segundo as Unidades da Federação - Brasil 2004

(continuação)

\begin{tabular}{|c|c|c|c|c|c|c|}
\hline \multirow{2}{*}{$\begin{array}{l}\text { Unidade } \\
\text { Geográfica }\end{array}$} & \multicolumn{6}{|c|}{ Onde estão sendo usados os microcomputadores } \\
\hline & $\begin{array}{l}\text { Dependência } \\
\text { Administrativa }\end{array}$ & $\begin{array}{l}\text { Em laboratórios, } \\
\text { salas de informática }\end{array}$ & $\begin{array}{c}\text { Em salas } \\
\text { de aula }\end{array}$ & Em Biblioteca & $\begin{array}{l}\text { Em sala de } \\
\text { professores }\end{array}$ & $\begin{array}{l}\text { Em outros } \\
\text { locais }\end{array}$ \\
\hline \multirow{3}{*}{$\begin{array}{l}\text { Rio Grande } \\
\text { do Norte }\end{array}$} & Total & 311 & 23 & 59 & 56 & 259 \\
\hline & Pública & 114 & 5 & 7 & 16 & 151 \\
\hline & Privada & 197 & 18 & 52 & 40 & 108 \\
\hline \multirow{3}{*}{ Paraíba } & Total & 301 & 39 & 67 & 108 & 268 \\
\hline & Pública & 128 & 11 & 18 & 66 & 127 \\
\hline & Privada & 173 & 28 & 49 & 42 & 141 \\
\hline \multirow{3}{*}{ Pernambuco } & Total & 1.122 & 104 & 210 & 262 & 798 \\
\hline & Pública & 514 & 19 & 29 & 127 & 340 \\
\hline & Privada & 608 & 85 & 181 & 135 & 458 \\
\hline \multirow{3}{*}{ Alagoas } & Total & 171 & 13 & 34 & 29 & 97 \\
\hline & Pública & 64 & 2 & 6 & 5 & 45 \\
\hline & Privada & 107 & 11 & 28 & 24 & 52 \\
\hline \multirow{3}{*}{ Sergipe } & Total & 137 & 9 & 23 & 25 & 89 \\
\hline & Pública & 61 & 4 & 4 & 8 & 49 \\
\hline & Privada & 76 & 5 & 19 & 17 & 40 \\
\hline \multirow{3}{*}{ Bahia } & Total & 986 & 117 & 306 & 488 & 1.217 \\
\hline & Pública & 527 & 40 & 134 & 326 & 767 \\
\hline & Privada & 459 & 77 & 172 & 162 & 450 \\
\hline \multirow{3}{*}{ Sudeste } & Total & 14.520 & 1.857 & 3.330 & 3.862 & 8.893 \\
\hline & Pública & 7.487 & 670 & 1.132 & 2.026 & 4.764 \\
\hline & Privada & 7.033 & 1.187 & 2.198 & 1.836 & 4.129 \\
\hline \multirow{3}{*}{ Minas Gerais } & Total & 2.520 & 242 & 645 & 787 & 1.585 \\
\hline & Pública & 1.329 & 57 & 273 & 476 & 821 \\
\hline & Privada & 1.191 & 185 & 372 & 311 & 764 \\
\hline \multirow{3}{*}{ Espírito Santo } & Total & 490 & 27 & 143 & 203 & 467 \\
\hline & Pública & 208 & 8 & 28 & 109 & 300 \\
\hline & Privada & 282 & 19 & 115 & 94 & 167 \\
\hline \multirow{3}{*}{ Rio de Janeiro } & Total & 2.910 & 296 & 514 & 662 & 1.821 \\
\hline & Pública & 987 & 98 & 169 & 325 & 935 \\
\hline & Privada & 1.923 & 198 & 345 & 337 & 886 \\
\hline \multirow{3}{*}{ São Paulo } & Total & 8.600 & 1.292 & 2.028 & 2.210 & 5.020 \\
\hline & Pública & 4.963 & 507 & 662 & 1.116 & 2.708 \\
\hline & Privada & 3.637 & 785 & 1.366 & 1.094 & 2.312 \\
\hline \multirow{3}{*}{ Sul } & Total & 5.122 & 622 & 2.066 & 2.806 & 4.138 \\
\hline & Pública & 3.350 & 324 & 1.175 & 2.178 & 2.956 \\
\hline & Privada & 1.772 & 298 & 891 & 628 & 1.182 \\
\hline \multirow{3}{*}{ Paraná } & Total & 1.880 & 186 & 727 & 989 & 1.674 \\
\hline & Pública & 1.170 & 68 & 408 & 771 & 1.208 \\
\hline & Privada & 710 & 118 & 319 & 218 & 466 \\
\hline
\end{tabular}


Tabela 9 - Número de escolas de educação básica que fazem utilização pedagógica da informática por local de utilização, segundo as Unidades da Federação - Brasil 2004

(conclusão)

\begin{tabular}{|c|c|c|c|c|c|c|}
\hline \multirow{2}{*}{$\begin{array}{l}\text { Unidade } \\
\text { Geográfica }\end{array}$} & \multicolumn{6}{|c|}{ Onde estão sendo usados os microcomputadores } \\
\hline & $\begin{array}{c}\text { Dependência } \\
\text { Administrativa }\end{array}$ & $\begin{array}{l}\text { Em laboratórios, } \\
\text { salas de informática }\end{array}$ & $\begin{array}{l}\text { Em salas } \\
\text { de aula }\end{array}$ & Em Biblioteca & $\begin{array}{l}\text { Em sala de } \\
\text { professores }\end{array}$ & $\begin{array}{l}\text { Em outros } \\
\text { locais }\end{array}$ \\
\hline \multirow{3}{*}{ Santa Catarina } & Total & 1.225 & 213 & 569 & 981 & 1.139 \\
\hline & Pública & 829 & 133 & 354 & 827 & 871 \\
\hline & Privada & 396 & 80 & 215 & 154 & 268 \\
\hline \multirow{3}{*}{$\begin{array}{l}\text { Rio Grande } \\
\text { do Sul }\end{array}$} & Total & 2.017 & 223 & 770 & 836 & 1.325 \\
\hline & Pública & 1.351 & 123 & 413 & 580 & 877 \\
\hline & Privada & 666 & 100 & 357 & 256 & 448 \\
\hline \multirow{3}{*}{ Centro-Oeste } & Total & 1.876 & 132 & 466 & 863 & 1.674 \\
\hline & Pública & 858 & 30 & 118 & 554 & 1.084 \\
\hline & Privada & 1.018 & 102 & 348 & 309 & 590 \\
\hline \multirow{3}{*}{$\begin{array}{l}\text { Mato Grosso } \\
\text { do Sul }\end{array}$} & Total & 441 & 25 & 87 & 195 & 423 \\
\hline & Pública & 228 & 5 & 21 & 133 & 296 \\
\hline & Privada & 213 & 20 & 66 & 62 & 127 \\
\hline \multirow{3}{*}{ Mato Grosso } & Total & 332 & 25 & 92 & 329 & 412 \\
\hline & Pública & 211 & 16 & 40 & 275 & 327 \\
\hline & Privada & 121 & 9 & 52 & 54 & 85 \\
\hline \multirow{3}{*}{ Goiás } & Total & 723 & 52 & 161 & 182 & 641 \\
\hline & Pública & 314 & 5 & 38 & 85 & 389 \\
\hline & Privada & 409 & 47 & 123 & 97 & 252 \\
\hline \multirow{3}{*}{ Distrito Federal } & Total & 380 & 30 & 126 & 157 & 198 \\
\hline & Pública & 105 & 4 & 19 & 61 & 72 \\
\hline & Privada & 275 & 26 & 107 & 96 & 126 \\
\hline
\end{tabular}

Fonte: MEC/Inep 


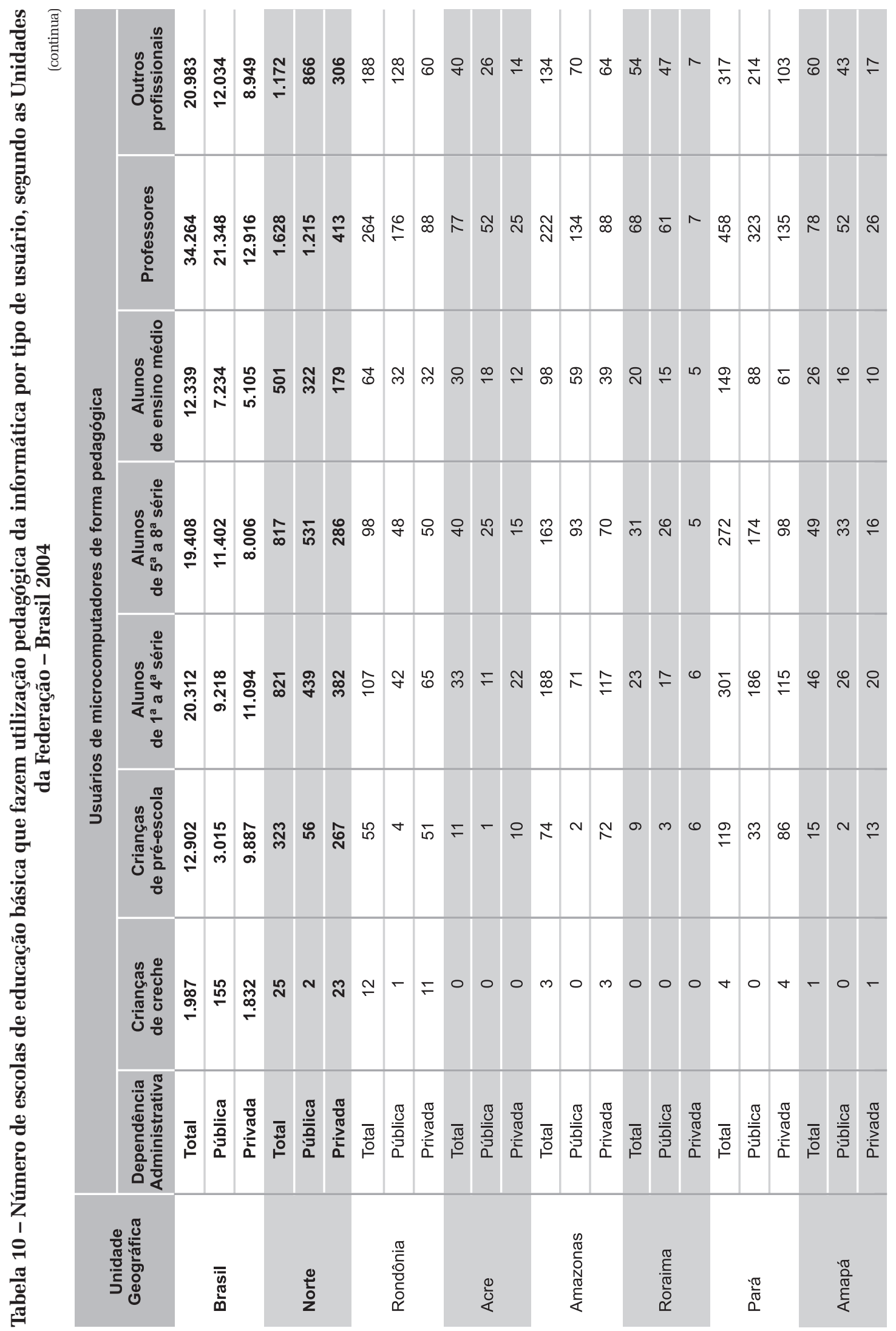




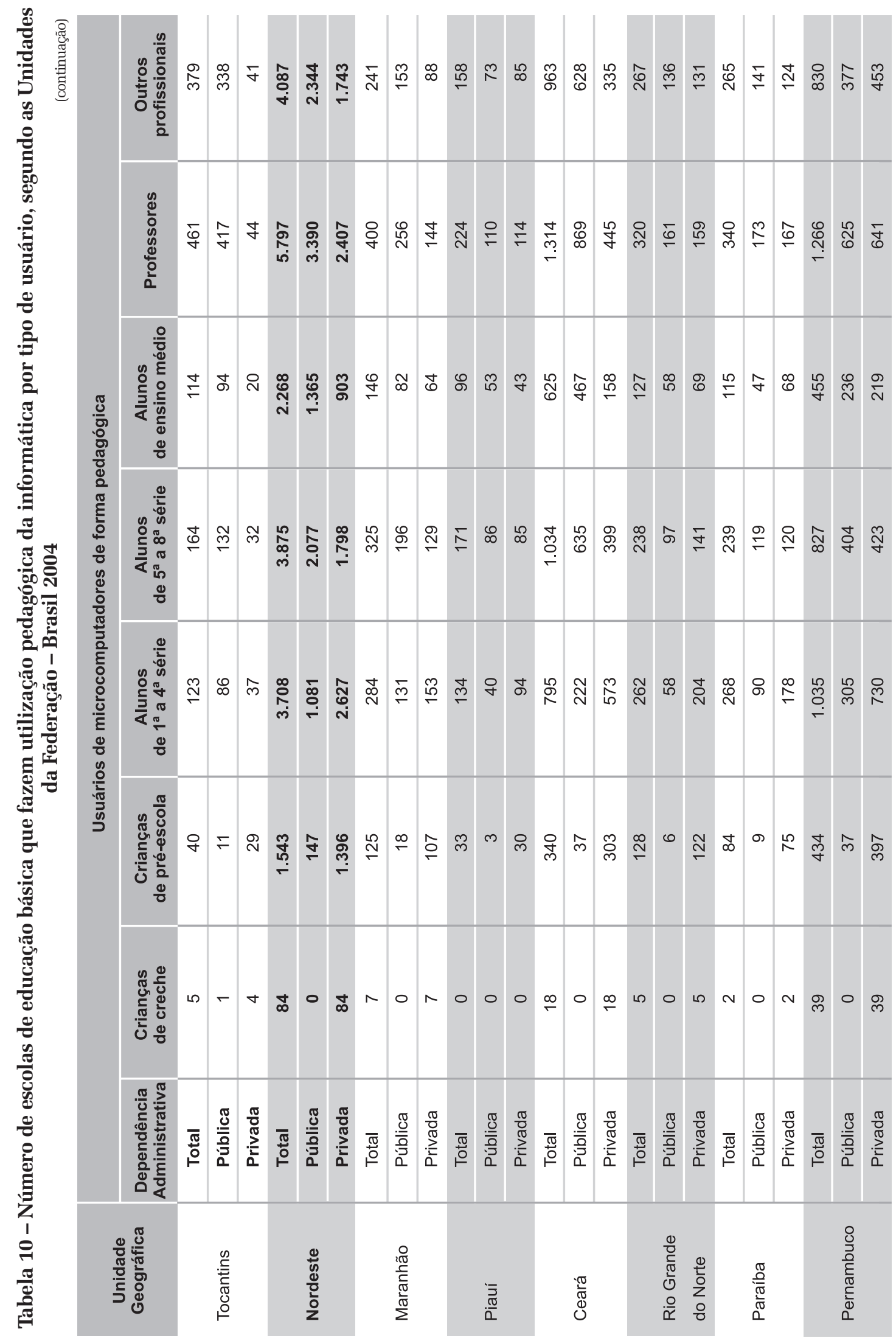




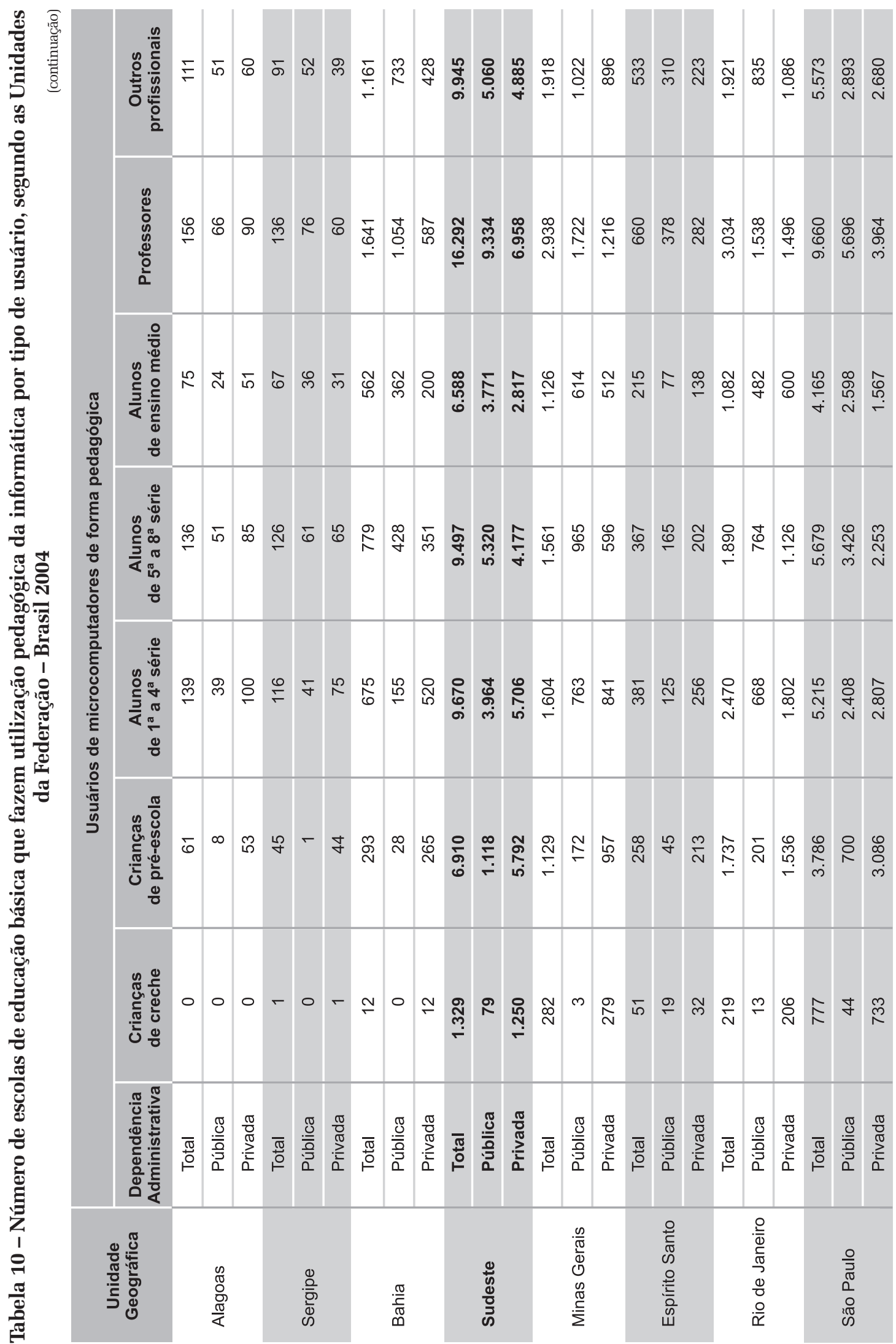




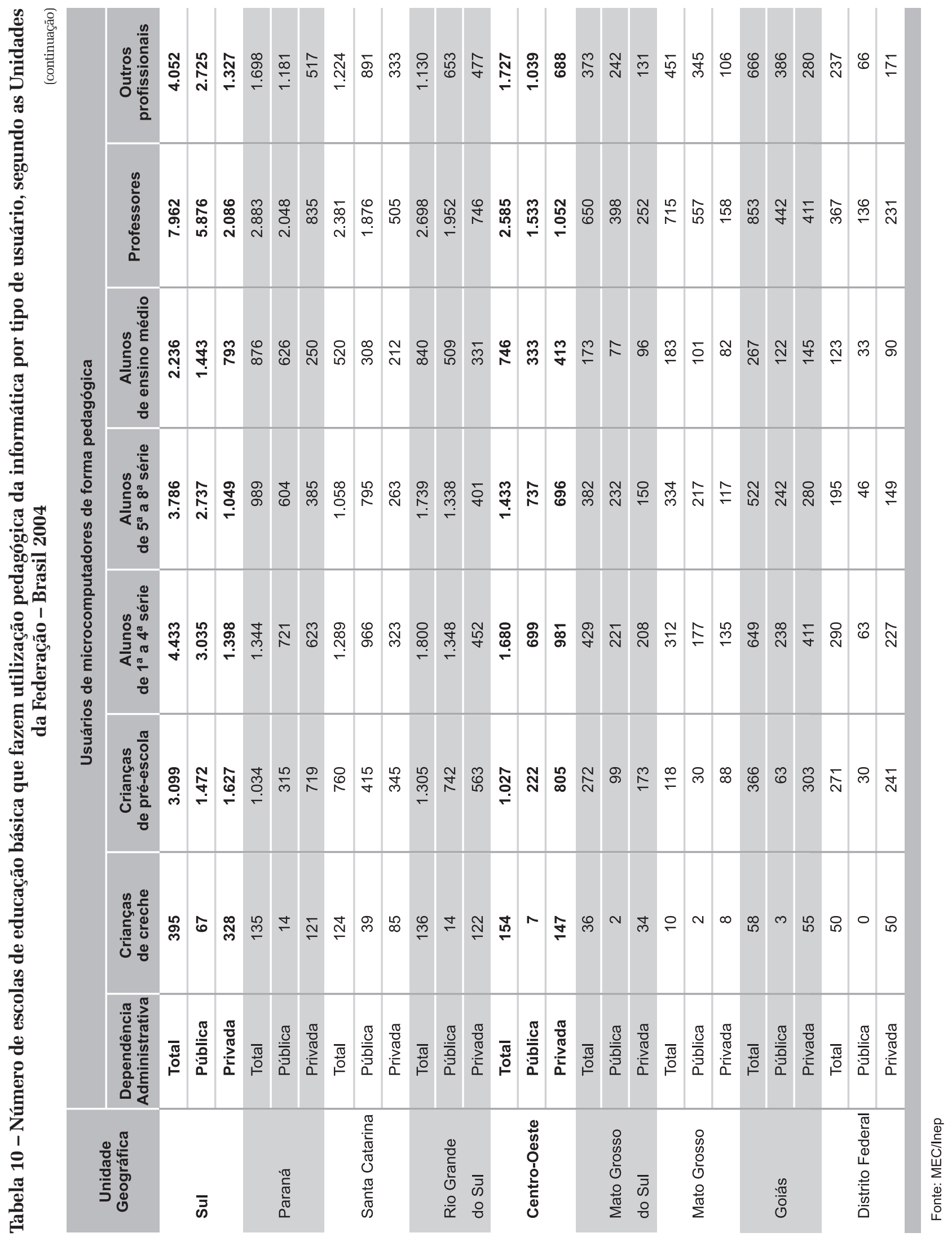

